\title{
O exercício da sexualidade em fins do século XX
}

Nelson Vitiello'

Segundo os dados disponíveis, a vida surgiu em nosso planeta há cerca de 4 bilhões de anos. Durante os primeiros 3 bilhões de anos, no entanto, os seres vivos mantiveram-se sob formas bastante rudimentares, que se reproduziam por divisão simples, brotamento ou esporulação. A reprodução ocorria assim de maneira assexuada, isto é, cada indivíduo era capaz de produzir organismos iguais a si mesmo, sem o concurso de um "parceiro". É o tipo de reprodução que ainda hoje encontramos em organismos primitivos como as amebas, por exemplo.

Podemos deduzir ter tido essa forma de reprodução um relativo sucesso, pois a vida se manteve até que surgisse um método mais eficiente. As modalidades assexuadas apresentavam a Grande vantagem de demandar relativamente pouca energia, por não haver necessidade de manter estruturas especializadas para a reprodução nem mecanismos complexos de produção de gametas, busca de parceiros, etc. Ao lado desse fato, porém, a uniformidade e a falta de variedade entre os indivíduos eram 
notáveis, o que certamente representou uma desvantagem sob o ponto de vista evolutivo.

Há cerca de um bilhão e meio de anos, no entanto, surgiu um mecanismo diferente, que denominamos de "reprodução sexuada". Esse mecanismo implica obrigatoriamente na mistura dos elementos de informação genética (genes, dispostos em cromossomos no núcleo das células) de organismos diferentes. Cada organismo produz uma célula especializada (gameta) que, unindo-se com similar originada de outro indivíduo, num processo denominado "fecundação", dá origem a uma célula nomeada zigoto, que possui uma coleção dupla desses elementos. Da combinação e recombinação dos elementos de informação genética dos organismos "pais", originam-se organismos "filhos", que possuem uma mistura de características ou até características novas, que aparentemente não existiam na geração anterior.

Durante todos os milhões de anos em que a reprodução sexuada vem sendo utilizada pelos mais diferentes tipos de plantas e animais, vários "modelos" foram usados. O que teve mais êxito - tanto que é ainda o utilizado por plantas e animais superiores - é o que a espécie humana usa. Nesse modelo existe uma diferenciação sexual acentuada, com presença de gônadas (testículos e ovários), órgãos especializados para a produção de gametas (espermatozóides e óvulos), que são as células cujo encontro (fecundação) írá formar o novo indivíduo.

Entre os animais superiores existe um forte instinto que leva o indivíduo à busca da reprodução, em processos quase sempre bastante complexos. Analisando-se em especial as aves e os mamíferos, animais evolutivamente mais próximos de nós, pode-se observar que existe todo um ritual cercando o ato sexual, como parte de uma armadilha montada pela natureza para a perpetuação das espécies. Alguém já disse que a galinha foi a melhor maneira que o ovo encontrou para produzir outro ovo; em linhas gerais, pode-se também dizer que o adulto foi a melhor maneira que o gene (molécula protéica que porta os caracteres hereditários) conseguiu inventar para se perpetuar.

Nossa própria espécie, porém, embora do ponto de vista estritamente biológico apresente um padrão de ciclo reprodutivo exclusivamente sexuado, basicamente idêntico ao de todos os outros mamíferos, "inventou" uma característica ímpar. Graças a complexos e sutis mecanismos neuro-endócrinos apresentados pelas mulheres, é-nos permitido lesar a mãe natureza a praticar prazerosamente relações sexuais mesmo (ou talvez principalmente) sem finalidades reprodutivas. 
A sexualidade humana assim, ao contrário da encontrada em todos os outros mamíferos, excede em Muito o mero componente biológico, deixando de ser um simples instinto associado à reprodução. Nas demais espécies o coito só é praticado quando a se existem condições para a reprodução, isto é, durante o período fértil das fêmeas. Manifestações Outras da sexualidade - como a masturbação e a homossexualidade - são observadas apenas esporadicamente, e sempre entre os machos. Concomitantemente com o ciclo menstrual (outra inovação humana), entretanto, as fêmeas de nossa espécie adquiriram a capacidade, única no reino animal, de se excitarem a terem prazer sexual independentemente da atividade reprodutora. Somos os únicos, por exemplo, a manter vida sexual ativa mesmo em períodos inférteis e até durante a gestação.

Além dessa característica -talvez até por causa dela -nossa sexualidade apresenta um componente psicossocial que se sobrepõe ao biológico, sendo até mesmo mais notável.

Com o surgimento dos primeiros bandos de hominídeos apareceu a necessidade de uma, certa organização social, que se complexificou na medida em que foi se desenvolvendo uma "cultura", base da civilização. Dentro dessa cada vez mais complexa organização social, inevitavelmente foram surgindo regras para normatizar os diversos aspectos das atividades dos indivíduos, inclusive a sexual. Assim, mesmo quando possuído por intenso desejo sexual, o macho passou a só poder praticar o coito com uma fêmea dentro de certas condições, também impostas quando a situação é a inversa, isto é, quando é a fêmea que se encontra excitada. Criou-se então todo um ritual de complexo simbolismo - que culminou do casamento, tal como o conhecemos - para normatizar o que é socialmente aceitável em matéria de exercício da sexualidade.

Do ponto de vista psicológico, na medida em que foi surgindo nos hominídeos a consciência do "eu", foram-se também elaborando parâmetros para auto-avaliação de desempenho, consciência de aceitação, sensação de adequação ao meio, etc. Esses aspectos intrapsíquicos, tão valorizados que passaram a ser medida da própria existência ("penso, logo existo"), possuem imenso papel no exercício da sexualidade, ao lado do componente social.

A sexualidade, entendida a partir de um enfoque amplo a abrangente, manifesta-se em todas as fases da vida de um ser humano e, ao contrário da conceituação vulgar, tem na genitalidade apenas um de seus aspectos, talvez nem mesmo o mais importante. Dentro de um contexto mais amplo, pode-se considerar que a influência da sexualidade permeia todas as manifestações humanas, do nascimento até a morte. 
No entanto, durante a maior paste da história da humanidade essa influência foi negada, em especial entre os povos ligados às tradições judaicas a cristãs, atualmente representada pela assim denominada "civilização cristã ocidental-.

O curioso desse evento é que na tradiçã o bíblica mais antiga que conhecemos, a tradição javista (aproximadamente 950 a.C.), não existe nenhum desprezo pela natureza sexual do homem. De fato, a leitura do "Gênesis" permite a interpretação de estar a sexualidade ali exposta apenas como mais um aspecto da vida, nem inferiorizado nem enaltecido em relação a qualquer outro. Assim, a exegese mais isenta apresenta como motivação divina para a criação da mulher apenas a atenuação da angústia da solidão vital do homem. A interpretação patrística da Bíblia, porém, que há tantos séculos vem influenciando nossa cultura, considera o sexo como um mal necessário, admissível apenas por ser indispensável à reprodução da espécie. Inaugurou-se, partir dessa interpretação, a confusão entre sexualidade e genitalidade, que perdura até nossos dias.

Para bem compreendermos a motivação social para a enorme repressão às manifestações prazerosas da sexualidade feita pela cultura judaica, é importante que nos reportemos às suas origens. Na época em que essas tradições foram estabelecidas, Israel era uma pequena tribo, igual a dezenas de outras, que ora vagavam pelo Oriente Médio, ora se estabeleciam em determinados locais. Os judeus tinham, necessariamente, que incentivar a diferenciação entre seu povo e os outros, para poder estabelecer a consciência de uma "nacionalidade". Os outros povos da época e da região (cananeus, filisteus, etc.) eram todos politeístas, com uma enorme multiplicidade de deuses e deusas, todos eles altamente sexuados. Segundo a mitologia da maioria desses povos. o universo teria se originado de uma união (leia-se "coito") entre dois deuses, quase sempre irmãos.

Assim, para se diferenciar desses outros povos, os israelitas cultuam um deus assexuado (Javé), que cria o Universo a partir do nada, isto é, sem parceria, de maneira assexuada. Nota-se assim que para os israelitas a sexualidade perde os atributos divinos, deixando de haver uma "sexualidade sagrada", cultiva nos templos, como era comum entre os seguidores das outras religiões.

Além disso, pelas suas características expansionistas a guerreiras, Israel necessitava de muitos, muitos soldados. Como a mortalidade infantil era muito alta, a solução encontrada foi estimular o aumento da natalidade, devendo todos praticarem apenas o "sexo-reprodução". O "sexo-prazer", assim, passou a ser mal visto e a esterilidade considerada a maior das maldições. A anticoncepção, em qualquer modalidade, passou a ser uma ofensa aos conterrâneos e a religião, sendo Onã (Gênesis, 38: 8) fulminado por 
Javé por haver usado de subterfúgios anticonceptivos. A masturbação e a homossexualidade masculina eram abominações terríveis, enquanto a homossexualidade feminina era um crime tão horrível que sequer era coitada.

A sexualidade foi assim, seguindo esse caminho, deixando de ser fonte de prazer, passando a ser apenas mais uma das "obrigações" que os bons patriotas judeus deveriam cultivar. Esse comportamento anti-sexual foi cristalizado em todo um ritual de Purificação das mulheres durante e após as menstruações. Consideradas "impuras" nesses períodos, deviam as ortodoxas ainda devem - se submeter a todo um processo de purificação que, por durar vários dias. termina próximo ao período ovulatório seguinte, levando como consequiência a um aumento das taxas de reprodução.

Não que os judeus não conhecessem o prazer advindo da sexualidade; conheciam-no sim e, embora não fosse considerado louvável, era ao menos socialmente tolerável... para os homens! Basta ler no Velho Testamento o Cântico dos Cânticos para que se tenha uma boa visão do erotismo que permeava a vida $\mathrm{r}$ os pensamentos de, ao menos, alguns privilegiados como o Rei Salomão. No geral, entretanto, podemos dizer que a cultura judaica é sexualmente repressora, machista e sexista.

Com o surgir do cristianismo as coisas se mantiveram nos mesmos moldes, ou talvez até piores, sob certos aspectos. Os cristãos dos primeiros séculos, como os primitivos israelitas, eram minoritários e tinham que se esforçar para diferenciar-se das outras religiões vigentes no Império Romano. Mesmo os sacerdotes cristãos, nos primeiros séculos, casavam-se regularmente e mantinham vida sexual ativa. Embora a obrigatoriedade do celibato sacerdotal viesse sendo discutida desde o Concílio de Ancisa, em 314 d.C., foi só a partir de determinação expressa do Papa Gregório VII, em 1.075, que o matrimônio passou a ser proibido para os sacerdotes católicos.

Assim, repetiram os cristãos o mesmo modelo repressor da sexualidade herdado dos judeus. No entanto, embora as igrejas cristãs (especialmente a Católica) sejam no geral bastante repressoras em termos de sexualidade, vale a pena lembrar que não existe registro, em todo o Novo Testamento, de qualquer ato ou palavra repressora que possa ser atribuída ao próprio Jesus. Pelo contrário, em alguns episódios (o referente à mulher adúltera, por exemplo, em São João, 8: 7), suas palavras demonstram uma tolerância e uma compreensão das fraquezas e dos desejos humanos absolutamente incompatível com a ferocidade com que seus seguidores reprimiram (e alguns ainda reprimem) as manifestações da sexualidade. Aliás, cite-se como um registro curioso que Aristóteles, o grande Aristóteles tão querido dos teólogos medievais da Igreja Católica, expressava sérias dúvidas sobre seja mulher teria ou não uma alma. Felizmente para as mulheres, 
os prelados presenter concluíram que sim. Note-se que essa discussão ocorreu apenas a escassos XX séculos!

Considerando tudo isso, podemos dizer que pela vertente cultural judaica cristã herdamos uma visão extremamente repressor-a da sexualidade, mais acentuadamente marcada, como sempre, para o contingente feminino.

Nossa outra vertente, a greco-romana, embora por motivos diferentes também exerceu repressão sobre a sexualidade, ao menos sobre a feminina. Os homens gregos tinham a busca do prazer como ideal, sendo permitidas e até incentivadas quaisquer experiências hedonistas. Esse prazer, no entanto, era buscado fora de casa, entre as prostitutas (hetairas e pornois) e os com efebos. As esposas eram quase que prisioneiras de uma dependência doméstica - o gineceu, sendo mantidas como embrutecidas e emburrecidas máquinas de administrar casas e fazer filhos, sendo-lhes negado qualquer direito ou qualquer prazer. A cultura grega foi, assim, machista, hedonista e, do ponto de vista da mulher, repressora.

Os romanos, ao menos em certos períodos e para certas classes sociais, foram um pouco mais liberais. Vista como um todo, entretanto, a culture romana foi bastante machista, sendo o prazer permitido apenas aos homens e a algumas privilegiadas mulheres.

Assim, como se vê, nossas raízes culturais estão impregnadas de uma visão distorcida da sexualidade, onde a prática da repressão é o comportamento usual, ao menos para as mulheres, quando não também pare os homens. Em outras palavras, em nossa cultura, ao menos até bem recentemente, o machismo reinou impunemente.

Embora nossa civilização tenha, nos últimos séculos, vivido alguns momentos de maior liberalidade, essa visão distorcida da sexualidade foi a tônica principal, mantida durante todos esses séculos em que ela vem se cristalizando. Diga-se de passagem que, mesmo em seus momentos de mais liberdade, o exercício pleno da sexualidade sempre foi apanágio das pessoas adultas, que negam vêem com maus olhos a sexualidade dos adolescentes, ridicularizam as manifestações sexuais da terceira idade e negam - ao menos negaram até as poucas décadas - a sexualidade na infância. De fato, foi necessário que surgisse um Freud, no apagar das luzes do século XIX, pare que "descobríssemos" que a sexualidade existe e se manifesta, ainda que de forma diferentes, durante tods a duração da vida humana.

O machismo, como instrumento do patriarcalismo que herdamos de nossos antecessores culturais, tem pelo menos seis mil anos de história registrada, e possivelmente muitos milênios a mais. Ainda que os teóricos da árqueo-antropologia não cheguem a um consenso, é praticamente certo que 
o machismo tenha surgido a partir da época em que o homem reconheceu seu papel no processo da reprodução. Até esse momento, julgava-se, a mulher era capaz de fazes filhos por sua própria conta, sem o concurso do macho e, ainda segundo a maioria dos estudiosos desses temas, os primeiros Deuses eram de sexo feminino.

Usado inicialmente como instrumento preservador do poder masculino, o machismo deu tão certo, como recurso, que até hoje ainda não conseguimos nor livrar adequadamente de suas conseqüências.

\section{ALGUMAS DAS CARACTERÍSTICAS DE NOSSA ÉPOCA}

Não se pode negar que a civilização está vivenciando, neste fim de século, uma situação de crise que se manifesta em várias frentes; vivemos uma época de crise dos valores morais e éticos, uma crise econômica e política, etc.

Essa situação é resultante de um sem numero de fatos ocorridos em nossa história longínqua ou recente, que condicïonaram o surgir da atual fase. Claro é que, a gosto de cada um, pode-se pinçar este ou aquele acontecimento e listá-lo como de fundamental importância. Alguns deles, entretanto, são tão relevantes que não podemos deixar de considerá-los. Assim, apenas pare registro, podemos citar a exacerbada urbanização, o aperfeiçoamento dos meios e técnicas de comunicação de massa, a uniformização dos costumes e o uso da sensualidade como método de marketing, apenas para ficarmos dos mais importantes. Inegavelmente, a dinâmica de vida humana mudou, e com ela mudaram os costumes, as necessidades. os problemas e a própria organização da família, centro irradiador do processo educational. Daquela família estendida, em que conviviam num mesmo espaço três ou mais gerações, com grande número de indivíduos e vários colaterais e agregados, passou-se à família nuclear, na qual convivem somente os pais e um ou dois filhos, que freqüentemente apenas se vêem rapidamente, na maioria dos dias. Essa mudança da estrutura familiar afrouxou os laços de união entre seus membros e trouxe, como conseqüência, a quase total abolição da transmissão de conhecimentos, tradições e costumes entre as gerações. A cultura, em seu conceito antropológico, deixou de ser transmitida de geração à geração, pela crescente perda de prestígio das cgerações mais idosas, que vêem seu papel de transmissor cultural cada vez mais ocupado pelos meios de comunicação de massa. 
Os fatores aqui tão superficialmente citados contribuem, todos eles, para uma nova maneira de viver; não nos cabe (nem teria qualquer sentido) um julgamento de valores, no sentido saudosista de louvar os velhos tempos. ou de entoar loas às conquistas tecnológicas de nossa época. O que desejamos é, tão somente, assinalar que a sociedade mudou, e com ela mudamos todos nós adultos, crianças e adolescentes. E é dentro dessa linha de mudanças que devemos nos esforçar para compreender os comportamentos a atitudes assumidas por nossos contemporâneos.

Até bastante recentemente, digamos até há cerca de 50 anos, a sexualidade era vista e vivida como algo de sujo, pecaminoso à culposo. Nesse esquema, o era comum que as pessoas tenham uma noção distorcida da sexualidade, deixando de vê-Ia como algo positivo, como algo de bom e belo, como um dom. A partir dos movimentos de contestação social surgidos na década de 50, no entanto, muitas coisas mudaram. Embora ainda carregue muito do ranço repressor antigo, a visão social do exercício da sexualidade já começa a ter um mais intenso componente de tolerância,

Inegavelmente, nos últirnos anos, sexualidade tem sido vista com mais naturalidade e, em certas condições, até mesmo estimulada. Curiosamente, tem-se observado em nível mundial um fenômeno de supervalorização da atividade sexual, apresentando como meta suprema a obrigatória o orgasmo, considerado como o mais precioso bem a que se pode almejar. Nessa acepção é -obrigação" do homem dar orgasmos à mulher, como se orgasmos fossem presentes que a onipotência masculina possa distribuir a seu bel prazer. A mulher, por sua vez, para considerar-se "verdadeiramente mulher", deve ter orgasmos (de preferência múltiplos), sem o que considera-se uma fracassada.

Soma-se a essa obrigatoriedade orgásmica a de ter intensa e precoce vida sexual, sendo aqui o "intensa" medido pela freqüência de coitos, e não por sua qualidade. Em suma, para se considerarem "normais", as pessoas devem ter intensa vida sexual, atingindo sempre, em todas as relações, o famoso orgasmo.

Esse estímulo à sexualidade vem sendo intensamente difundido pelos meios de comunicação de massa e pelas novas e agressivas técnicas de marketing. Hoje em dia é fácil a constatação de serem intensamente utilizados o erotismo e a sexualidade como técnica de incentivo ao consumo.

Os homens, de maneira geral, apresentam evidente temor de desempenho, que associado a um aprendizado inadequado freqüentemente leva à ejaculação prematura, quando não à impotência. As mulheres, vítimas dessa mesma "educação", buscam desesperadamente um orgasmo... que não vem. As estatísticas, mesmo as mais otimistas, mostram que cerca 
da metade das mulheres desenvolve uma disfunção sexual, acompanhadas por perto de $35 \%$ dos homens adultos.

Vimos assim assistindo, nos dias correntes, o desenrolar de uma profunda luta no íntimo da maioria das pessoas que tem um pouco de sensibilidade para os problemas sociais. De um lado, adotamos um discurso bastante liberal (e estamos intelectualmente convictos) da necessidade da abolição de qualquer discriminação da qual a mulher possa ser vítima, bem como pelo fim de todos os preconceitos machistas dos quais nossa sociedade ainda está tão impregnada. De outro, por termos sido educados dentro desses mesmos preconceitos, somos ao mesmo tempo suas vítimas e seus agentes; embora liberais nas palavras, ainda somos repressores a preconceituosos nas ações. Essa dualidade se expressa em praticamente todas as áreas, e é bem nítida no que tange ao trabalho da mulher.

$\mathrm{O}$ modelo de comportamento feminino vigente até bem pouco tempo, de mulher exclusivamente dedicada aos afazeres domésticos, tornou-se bastante inadequado nos dias atuais, não sendo satisfatório nem para as mulheres nem para a maioria dos homens. De fato, o esquema da assim chamada "rainha do lar", isto é, da mulher inteiramente presa à faina de lavar, passar, cozinhar, cuidar dos filhos, etc., tornou-se ultrapassado não apenas pela necessidade de que a mulher contribua com o orçamento doméstico, mas principalmente porque aquele alheamento aos problemas do mundo é altamente infelicitante para todos. Esse tipo de atividade transformar a mulher insatisfeita em companheira mal informada a desinteressante, em mãe neurotizante a neurotizada, enfim, em pessoa emocionalmente instável e com muito baixo nível de autoestima.

É evidente que existem exceções, mulheres que sentem-se felizes e realizadas zelando pela casa e pelos filhos, exercendo as assim chamadas "prendas domésticas "; tais "Amélias" são no entanto exceções cada vez mais raras. Curiosamente, no entanto, essas mulheres também são discriminadas (principalmente por outras mulheres), sendo hoje até mesmo um pouco ofensivo rotular uma mulher de "dona de casa". Essa expressão é capaz até de gerar culpa entre as mulheres assim vistas. Ficam as pobres mulheres sem opção, pois embora seja considerado humilhante ser uma simples dona de casa, são elas também discriminadas quando saem para trabalhar fora do lar.

Outras vezes, em lares de classe média ou alta, as mulheres se cercam de empregados para executar praticamente todo o trabalho do lar, incluindo-se nesse rol copeiras, jardineiros e motoristas, para que elas fiquem absolutamente sem nada para fazer. Essa situação, freqüente- 
mente incentivada por zelosos maridos, pode levar até a maior insatisfação, pois essas mulheres (que as mais críticas. apelidam de "dondocas") sentem-se quase que totalmente inúteis. Muitas dessas mulheres, por sentirem-se sem objetivos, sentem-se compelidas a vencer as resistências maritais e fazer um curso ou procurar uma atividade. Entretanto, enfrentam bastante dificuldade para conseguir trabalho por estarem já em faixa etária na qual as oportunidades de emprego são menores e por não terem as qualificações profissionais e a experiência que o mercado exige. Os empregadores, por seu lado, vêem essa mão de obra com certo grau de desconfiança, por considerá-la diletante a por temer que, frente as primeiras dificuldades, desistam do emprego. Por essas razões, essas mulheres ficam na curiosa situação de ao mesmo tempo precisarem trabalhar (até como uma forma de terapia), e de não necessitarem dos proventos desse trabalho para subsistência. Boa parte delas acaba se acomodando em uma situação intermediária, exercendo atividades beneficentes ou de voluntariado, ministrando aulas particulares, indo trabalhar meio período na empresa de um amigo ou abrindo, juntamente com amigas na mesma situação, pequenas empresas de comércio, quase sempre de comércio de roupas, perfumes, etc.

Evidentemente, esse quadro que estamos tentando esboçar diz respeito à mulher de classe média ou alta, e em ambiente urbano. Mulheres de nível socioeconômico e cultural menos privilegiado e aquelas residentes em áreas rurais enfrentam dificuldades diversas das que aqui analisaremos.

Finalmente, importa ainda considerar que não são apenas as mulheres casadas que enfrentam problemas para uma perfeita integração ao mercado de trabalho. De fato, solteiras, viúvas e separadas enfrentam os mesmos preconceitos e - quando tem namorados - a mesma pressão machista.

Existem vários óbices ao trabalho feminino, conhecidos de todos e que deixaremos de aqui abordar por não ser esse nosso tema central. Importa ter presente, no entanto, que a maioria das mulheres, para exercer atividade profissional remunerada, enfrenta uma série de conflitos, tanto a nível externo, social, como também vários e dolorosos conflitos de foro íntimo. Não bastassem as dificuldades a serem enfrentadas para batalhar um emprego, lutar por salários justos e merecer respeito e reconhecimento de sua capacidade laborativa, para a quase totalidade das mulheres assumir essas atividades desperta importantes conflitos emocionais, freqüentemente permeados de sensação de culpa. Culpa por infringir padrões cul- 
turais machistas e culpa por não conseguir ser aquela mulher fantástica que as revistas denominadas "femininas" apresentam como padrão de desejabilidade, isto é, aquela super-mulher que é ao mesmo tempo profissionais de sucesso, companheira interessante, anfitriã perfeita e dona de casa zelosa. Quando existem filhos, então, a sensação de culpa se agrava, pois a cada espirro ou febrícula, a cada nota insatisfatória na escola e a cada dificuldade que os filhos enfrentam, ela se auto-acusa (além de ser acusada por amigas e pelo marido) de omissão.

Para muitos maridos, por não terem tido o preparo cultural e emocional necessário, o fato de reconhecer o direito ou a necessidade de que a esposa exerça uma atividade laborial remunerada provoca irremediáveis feridas no orgulho machista. Desse despreparo originam-se situações de importantes conflitos internos a externos, que dão ao conjunto da atitude masculina um aspecto muito pouco coerente. De fato, ao lado de um discurso freqüentemente liberal, observa-se uma postura extremamente repressora. Essa verdadeira "esquizofrenia" comportamental obriga os desorientados homens a construir um complexo edifício de racionalizações, na tentativa de explicar o inexplicável, isto é, os motivos que o levam a ser genericamente favorável à liberação feminina... para as outras mulheres, e não para sua esposa.

Devemos ainda acrescentar à essa oposição marital a perspectiva de que sua esposa conheça, no trabalho, outros homens eventualmente melhores ou mais interessantes, o que desperta inevitavelmente o ciúme. Assim, são freqüentes os "pareceres" contrários ao exercício de atividade profissional de mulheres, exarados por marido que habitualmente disfarçam seus verdadeiros motivos sob um manto de racionalizações as mais diversas. Quando alguma coisa dá errado, desde uma panela de arroz queimado até um insucesso escolar do Júnior, esses maridos sempre tendem a acusar suas esposas de "abandono do lar". Os filhos, a medida em que crescem e incorporam cada vez mais intensamente o machismo vigente, vão também praticando uma chantagem emocional sobre a mãe, visando prendê-la no lar.

Outra situação bastante danosa para o relacionamento conjugal surge quando a mulher, por um motivo qualquer, tem maior sucesso profissional, tem um reconhecimento social maior ou, pura e simplesmente, ganha mais que o marido. Nessas situações, facilmente observáveis Por exemplo entre casais de médicos, a auto-estima dos maridos fica em níveis bem baixos, sendo para eles difícil aceitar que sua esposa seja mais vezes convidada para Congressos, tenha maior reconhecimento científico ou maior clientela que a sua. 
Por esses motivos, é imperioso reconhecer que a mulher, para exercitar uma profissão, é obrigada a vencer não apenas as dificuldades inerentes ao mercado de trabalho, que analisaremos a seguir, mas até mesmo a oposição dentro de seu próprio lar.

Como se tudo isso não bastasse, o leque de opções profissionais disponíveis às mulheres é notavelmente mais restrito do que o existente para os homens. Embora legalmente essa diferenciação não exista, na vida real todos sabemos que o exercício de determinadas atividades é, senão vedado, ao menos muito dificultado para as mulheres.

Essas restrições, historicamente, sempre existiram e foi apenas com muita luta, coragem a perseverança que algumas valentes pioneiras foram conquistando duramente o direito de exercer atividades consideradas “impróprias para mulheres". Na medicina, por exemplo, é de todos conhecido o fato de ser relativamente recente a "concessão" do direito de cursar faculdades, visto que Escolas Superiores e Hospitais não eram considerados lugares "apropriados" para mulheres. Aliás, em um parêntese, note-se que a atualmente verificada "invasão" de mulheres nas Faculdades de Medicina, onde se encontram turmas com mais da metade de mulheres, só ocorreu a partir do momento em que a profissão médica deixou de ser altamente rentável.

A curiosa hipocrisia legal que cerca esse fato é que em praticamente país nenhum, ao menos no Ocidente, existe qualquer limitação jurídica ao exercício profissional. No entanto, os preconceitos são tão disseminados, mesmo entre as mulheres, que sequer se julga estranho não existirem, por exemplo, mulheres pilotando aviões comerciais. Se analisarmos o fato com isenção de ânimo, entretanto, não conseguiremos encontrar um só argumento que possa dar uma explicação satisfatória para essa ausência.

Mesmo nas profissões em que mais freqüentemente se encontram representantes de ambos os sexos, existe uma discriminação de atividades. Assim, na Gerência de uma instituição bancária, por exemplo, existem atividades a serem predominantemente exercidas por mulheres, outras por homens. Existem até em certas empresas um acordo tácito, aceito mesmo pelas mulheres, de que determinadas atividades estão fora do alcance da capacidade feminina.

Os preconceitos estão tão firmemente estabelecidos e disseminados na sociedade, que freqüentemente profissionais de sexo feminino são discriminadas por outras mulheres. E experiência compartilhada por vários médicos de sexo masculino, ouvir de pacientes (mulheres) que tratavam-se com uma colega, mas agora, que o caso tende a uma solução 
cirúrgica, os procuraram... por "não confiarem em mulheres para cirurgias"!

No que diz respeito às tarefas domésticas, embora entre alguns casais mais jovens já se venha observando um certo grau de diversificação, ainda se está muito longe da divisão eqüitativa, mesmo entre esses casais. Nos moldes dos casamentos tradicionais, numericamente mais frequientes, a situação ainda é pior, pois os maridos se recusam terminantemente a realizar tarefas ditas "de mulher". Curiosamente, entre casais que poderíamos talvez rotular de pseudo-modernos, os homens exercem algumas dessas atribuições, apresentando entretanto uma alta cobrança emocional. Esse jogo é tão neuroticacnente engrenado que não é incomum observarmos, nesses casais, que a esposa expresse muitos agradecimentos pelo fato de o zeloso marido ter condescendido em lavar os pratos... que ele mesmo sujou!

Na realidade, embora o antigo esquema da "dona de casa" não seja mais admitido pela maioria dos casais, não se chegou ainda a um acordo sobre qual esquema poderia substitui-lo, pois tanto homens quanto mulheres ainda não aprenderam a dividir as tarefas domésticas eqüitativamente.

Assim, podemos concluir que do ponto de vista da organização estrutural da sociedade, ainda não chegamos a uma situação de igualdade e divisão de tarefas, embora tenhamos caminhado muito nessa direção na última, ou nas duas últimas gerações.

\section{O EXERCÍCIO DA SEXUALIDADE}

Até aqui, abordando as condições de vida de homens e mulheres de nossa época, temos concluído existirem desigualdades diversas que, embora numa trajetória cheia de percalços, estamos buscando solucionar. E no que diz respeito à sexualidade?

Sem dúvida, o surgir da AIDS e o melhor conhecimento das possibilidades de dano a saúde de outras doenças sexualmente transmissíveis, como o vírus do HIV, trouxeram para ambos os sexos uma nova consciência sobre as consequiências do exercício da sexualidade. Ainda que por vezes superestimadas e usadas como fator de repressão por estruturas sociais mais conservadoras, essas doenças sem dúvida levaram, pelo próprio risco a elas inerente, à possibilidade da discussão mais aberta sobre o sexo. Mesmo levando a exageros de interpretação, passando o sexo a ter uma conotação de risco de morte, essas doenças trouxeram como conseqüência 
o incremento do estudo mais aprofundado das condições de exercício da sexualidade, carreando verbas antes impensáveis para o planejamento da educação sexual e para a difusão de conhecimentos. O exercício da sexualidade para a maioria das pessoas foi sem sombra de dúvida afetado, sendo hoje comum o temor à promiscuidade sexual e à prática inconseqüente do sexo.

No entanto, mesmo em não se considerando essas infecções, podemos constatar importantes mudanças, em especial no que diz respeito e posição feminina.

Chegamos ao final do século XX com as mulheres buscando o equilíbrio. Os ideais dos movimentos feministas mais radicais a extremistas das décadas de 40 e 50 vem sendo substituídos por posições mais lúcidas, harmônicas e coerentes. Se ainda não encontraram soluções para todos os problemas vivenciais que pluri-milenarmente as vem afligindo, sem dúvida as mulheres tem hoje uma visão mais clara do caminho a ser seguido para lá chegar. A nova mulher, que está emergindo desse processo, tem características bastante distintas das mulheres das gerações que as precederam.

Um número cada vez maior de mulheres busca instrução e trabalho num mercado que, embora ainda um pouco hostil, vai-se paulatinamente abrindo, graças ao seu denodado trabalho. Tornam-se, em número cada vez maior, financeira e emocionalmente independentes, passando a buscar não mais um macho protetor-patrocinador, como suas antecessoras de outras épocas, mas sim um companheiro com quem partilhar suas vidas, suas alegrias e tristezas, seus sucessos e fracassos. As mulheres, em suma, conseguiram definir suas metas e expressar seus anseios, na busca de uma situação que, embora ainda não tenha sido alcançada, ao menos tem já seus caminhos definidos.

E os homens? Educados que (ainda) são para terem um bom desempenho em qualquer coisa que façam (sexo inclusive), e não para serem felizes, os homens estão ainda perdidos com as novas posições e aspirações de suas companheiras. Passam suas vidas sempre tentando provar algo, tornando-se cada vez mais difícil que se sintam confortáveis com as novas noções de papéis sexuais.

Enquanto as mulheres vão buscando e encontrando soluções para uma série de problemas que historicamente as afligiam, os homens - em sua maioria -encontram-se perdidos, alijados (ou recusando-se a participar) desse processo.

Ainda que freqüente liberais nos discursos a grande maioria dos homens, lamentavelmente, ainda se aferra aos preceitos a preconceitos machistas com uma pertinácia espantosa, sendo na realidade repressores 
e reprimidos na atuação. Baseando sua auto-estima na pretensa superioridade que o machismo lhes conferia, Muitos dos homens atuais sentem-se perdidos quando, até por um dever de racionalidade, devem renegar a esse machismo. Para esses homens, a noção de igualdade tem um inegável sabor de inferioridade, levando-os a lidar inadequadamente com a "nova mulher", que vem emergindo nos últimos anos. A insegurança, a fragilidade e o desempenho dos "machões" tem levado muitos deles a sentirem-se acuados quando devem lidar com situações em que as mulheres tomam as iniciativas que, historicamente, eram apanágio masculino. Assim, sentir-se assediado por mulheres desperta neles uma evidente sensação de desconforto, que também se manifesta a partir do momento em que as mulheres ("suas" mulheres, vejam vocês!) passaram a exigir prazer e a atreverem-se a por em dúvida seu desempenho sexual! Milenarmente imbuídos da representação do papel de "caçador", na posição de "caça" sentern-se perdidos e desamparados. O que interpretam com "dominação" feminina é, para eles, um fardo por demais esmagador.

Acresça-se a isso o anatômico problema de serem extremarnente evidentes os seus "fracassos", enquanto a privilegiada anatomia feminina esconde deles os sucessos e insucessos sexuais das mulheres.

Os homens sempre foram, no sentido etimológico da palavra, péssimos amantes. Baseando suas atitudes numa desenfreada busca de desempenho, erotizaram eletivamente apenas o pênis, desenvolvendo uma relativa pobreza de seus mapas eróticos, ao contrario das mulheres, para as quais praticamente toda a pele reage eroticamente. As mulheres, além disso, privilegiam as emoções e a fantasia, o que faz com que possam viver em um mundo emocionalmente mais rico do que o de seus parceiros. Para o homem, no entanto, a ereção se constitui no ponto central da atividade sexual, sendo seus relacionamento; altamente genitalizados. A emoção, pelos preceitos machistas, é um terreno exclusivamente feminino, sendo negado ao homem manifestações como ternura, sensibilidade a afeto. Diz-se, em tom de graça mas não sem grande fundo de verdade, que o homem finge afeto para conseguir sexo, enquanto a mulher finge prazer no sexo, para conseguir afeto.

Os homens ainda matam por ciúmes, ou para "lavar a honra", como se o mundo não estivesse mudado e mudando. Sua ansiedade sexual e sua insegurança são tão evidentes que baseiam sua auto-estima em sua propalada capacidade de conduzir suas parceiras ao orgasmo, como se orgasmos fosse algo que alguém possa dar a outrem. A insegurança com que carregam sua superioridade faz com que ainda busquem palavras de reforço de suas mulheres, sobre suas performances. 
Essa postura masculina ainda é a vigente na maioria dos segmentos sociais, sendo freqüente também entre adolescentes. De fato, tendo-lhes sido ensinado na infância que os meninos são mais fortes do que as meninas, os adolescentes demoram a entender que tais ensinamentos não refletem uma verdade. A duras penas, aos poucos, vão percebendo que enquanto numa festa precisam se comportar como "machos" (brigando, fumando, bebendo, etc.) para tentar chamar a atenção das garotas, para elas basta usar um vestido um pouco mais ousado, ou fazer alguns trejeitos, o que é suficiente para atrair dezenas de candidatos. Ainda, por incrível que pareça, baseiam sua auto-estima... nas dimensões de seu pênis.

A insegurança do "machão" fica ainda maior quando percebe que enquanto para ele, após o orgasmo, torna-se absolutamente impossível novo ciclo de excitação (período refratário), sua companheira consegue excitar-se e estar pronta para outra relação num prazo de tempo incrivelmente curto. Fica assim, quase sempre, com a sensação de que as mulheres são muito difíceis de satisfazer, o que abala ainda mais sua auto-estima. A partir do momento histórico em que as mulheres adquiriram o direito de poder expressar seu desejo, esse fato tornou-se em mais um percalço a pesar sobre sua "masculinidade".

Os métodos anticoncepcionais que independem do controle masculino, tais como a pílula, o DIU ou mesmo a laqueadura tubária, também contribuem para aumentar a insegurança dos homens, tendo-se em vista que tais métodos são extremamente eficientes e fazem com que suas usuárias não temam indesejáveis gestações, podendo assim "traí-los" impunemente.

Em resumo, o homem precisa mudar. É fundamental que mude, para que possa redefinir seu papel nesse novo contexto social. É relevante que mude, que se dê o direito de expressar suas emoções, de ser sensível, de expressar suas dores, suas alegrias e seus amores, sem que com isso se sinta "menos homem". É importante que baseie sua auto-apreciação não no desempenho, mas na busca da felicidade. Enfim, é necessário que o homem se dê o direito de receber flores.

O homem precisa mudar. É cada vez mais urgente que mude, para tornar-se um digno companheiro dessas maravilhosas criaturas que estão emergindo do processo de conscientização feminina. 